\title{
Triggered Seismicity in Northern Algeria from a Statistical Modeling
}

\author{
L. Amir*, L. Abdessamed \\ Department of Geophysics, Faculty of Earth Sciences and Geography, USTHB, BP 32, Bab Ezzouar, 16111,Algiers, Algeria
}

Received October 12, 2020; Revised December 10, 2020; Accepted December 20, 2020

\begin{abstract}
Cite This Paper in the following Citation Styles
(a): [1] L. Amir, L. Abdessamed, "Triggered Seismicity in Northern Algeria from a Statistical Modeling," Civil Engineering and Architecture, Vol. 8, No. 6, pp. 1491-1496, 2020. DOI: 10.13189/cea.2020.080628.

(b): L. Amir, L. Abdessamed, (2020). Triggered Seismicity in Northern Algeria from a Statistical Modeling. Civil Engineering and Architecture, 8(6), 1491-1496. DOI: 10.13189/cea.2020.080628.
\end{abstract}

Copyright $\odot 2020$ by authors, all rights reserved. Authors agree that this article remains permanently open access under the terms of the Creative Commons Attribution License 4.0 International License

\begin{abstract}
Seismic clustering raises challenging questions concerning the nucleation process in regions marked by active faults. In this paper, we present a stochastic modeling approach to identify background and triggered seismicity in Northern Algeria. To perform the seismic clustering, we used the etasFLP package from the CRAN (Comprehensiv Archive Network) in R. The model was calibrated by testing and combining the FLP (Forward Likelihood Predictive) and ML(Maximum Likelihood) method for the non-parametric and the parametric parameters that describe the intensity function. On the whole, the results show that the greater contribution for events comes from the triggered earthquakes. The etasFLP package is suitable to describe the pattern for main shock and aftershocks sequences. Nevertheless, the discrepancies concern here the spatial distribution of the triggered events. In fact, the present modeling indicates the necessity to add, during the computation, additional terms for coefficients that represent external factors that influence the neighboring stress and would cause triggered events. Moreover, a database with more events could provide an accurate modeling that would represent the distribution between the background and the triggered events. The Northern Algeria is the location for diverse source of tremors and therefore, there is a need to identify clearly man-made activities that might trigger seismic sequence. The present work aims at proposing the application of the ETAS model for such purpose.
\end{abstract}

Keywords Earthquakes, Likelihood, Modeling, Northern Algeria, Induced Seismicity, Etasflp, Background Seismicity, Intensity Function

\section{Introduction}

Seismic clustering helps to define whether an event is independant or triggered and generated by either aftershocks or the increase of the pore pressure due to the presence of fluids. The rupture mechanism for an active fault is related to the static stress condition within a fault system. The tectonic loading is known to be the main mechanism that determines a background seismicity. In this case, the earthquakes are independant. On the other hand, the stress transfer to the neighboring region after the main shock or the stress increases related to the pore fluid pressure when fluids are migrating within the cracks or the active fault determines the induced or triggered seismicity.

Located between the converging Eurasian and African tectonic plates, the collision setting of Northern Algeria is prone to moderate to important and destructive earthquakes with magnitudes up to 7.5. Induced seismicity has already been identified as a potential source of a list of earthquakes in northern Algeria. Active faults related folds in the region (Chott El Hammam) have been mapped and considered potential locations for fluids migration related to hydrothermal springs [1].

On the 1st of January 1965, the Hodna plains were struck by a devastating earthquake, the largest event ever recorded and felt in the region at that time (Io= VIII (MSK); Ms=5.4) [2]. While describing the damage and the casualty distribution, Benouar [2] reported that a witness "saw the sky red as a blaze". He added that "the atmosphere was smelling sulphur gas". On February 1960, another earthquake hit the Melouza region (Beni-Ilmane) near the Djebel Choukchott (Io = VIII (MSK)) [2]. In addition to the reported damage and casualty distribu- 
tion, Benouar [2] revealed again the smell of sulphurous gas in all of the affected region.

In the aftermath of the 2010 Beni-Ilmane earhquake, which struck the Hodna-Biban region in May $2010 \quad(\mathrm{Mw}=5.5$, CRAAG), Abacha et al. [3] conducted a seismic tomography in the epicentral area. They found S-wave low velocities anomalies that coincide with the aftershocks areas. They proposed the existence of "high fluid contents that may have been released from deeper levels by fault movements during the earthquakes and migrated rapidly upwards". They searched for any source that could support their hypothesis for hydrocarbon reservoirs and revealed the existence of reports of oil investigations conducted during the 1990's in the South Tellian border region [3].The picture hereafter was taken during the aftershock sequences of the 2010 earthquake seismic crisis (Figure 1).

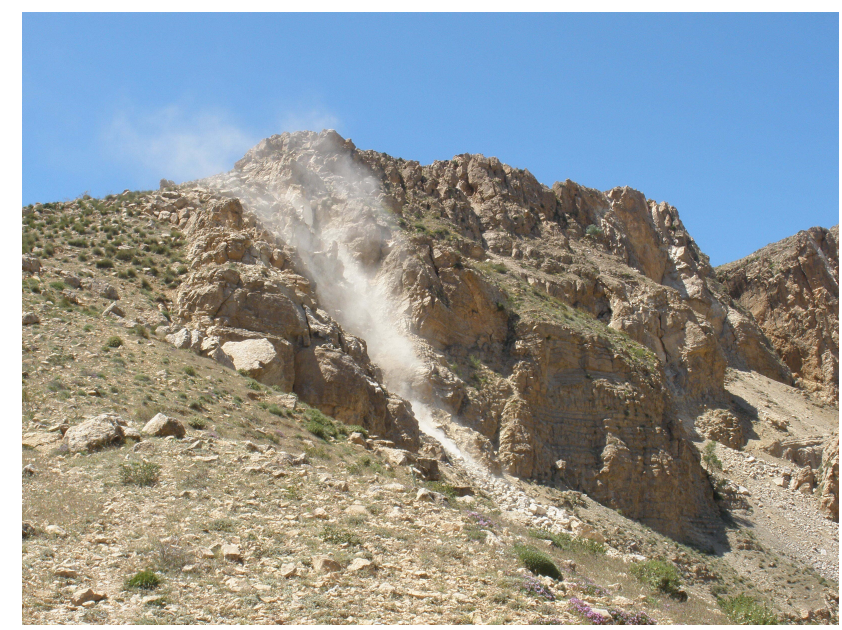

Figure 1. Vapor explosion / Gas in Beni-Ilman (credit photo: L. Amir, May 2014)

In this paper, stochastic modeling is proposed to describe the seismic pattern in northern Algeria. To this end, a seismic clustering is applied using the series of package in $\mathrm{R}$ developped by the CRAN (Comprehensive R Archive Network). Defining the nature of the seismicity is at the core of several models that aims to cluster earthquakes. On the one hand, the tectonic setting of the country displays several fault systems that may interact with one another. On the other hand, the local context is sometimes in favor of migration of fluids in deeper parts, which illustrates the conditions for geothermal exploration for example. All these processes define whether a region will be the location for a background or a triggered seismicity.

\section{Materials and Methods}

Stochastic modeling is used to quantify the observations so that any given event has a probability to be either a background event or a cluster event generated by others. All that theory is based on the space - time point process, which is a random collection of points, where each point represents the time and location of an event. In our case, the event is the occurrence of an earthquake that is localized with its latitude and longitude coordinates.

\subsection{Data}

Northern Algeria is marked by a regular shallow seismicity, with earthquakes that can reach magnitudes of 7 to 7.5 . These events are associated with a tectonic sketch that illustrates the convergence between the African and Eurasian continents. The three types of faults are there identified as active faults. The resulting thrusting, extensional and strike-slipping faults exist in a narrow geographical space, and stress is hence regularly redistributed in this closed band from the western to the eastern part of the country.

Here, we examined 2089 events from 1964 to 2019 with magnitudes above 2.5 . These events come from the ISC earthquake database available at http://www.isc.ac.uk/ . The selected studied zone covers an area that extends from $2^{\circ} \mathrm{W}$ to $8^{\circ} \mathrm{E}$ in longitude and $34^{\circ}$ to $38^{\circ} \mathrm{N}$ in latitude (Figure 2).

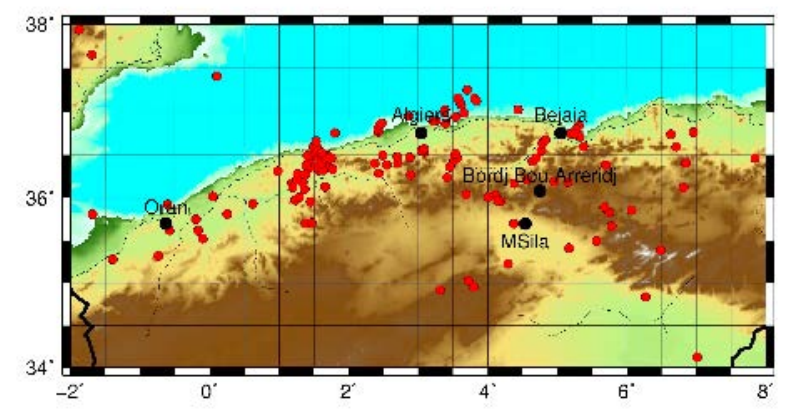

Figure 2. Location of the studied area. Circles represent the earthquakes events from 1964 to 2019. Magnitude are above 2.5 (http://www.isc.ac.uk/

\subsection{R package and the ETAS model}

The likelihood methods are used in statistical analysis to represent the distribution of data sets considering parameters that are likely to occur. The probabilities methods gave birth to a series of models to quantify the space-time processes. Ogata $[4,5]$ proposed an Epidemic-Type Aftershock Sequence model (ETAS), where a conditional intensity function is defined as the sum of the background and the triggered seismicity contributions (Equation 1). The point process represents the activity of earthquakes of magnitude Mo and larger in a region during a period of time.

In this work, the clustering method is based on stochastic modeling using the R-package. The package "etasFLP" corresponds to the mixed FLP (Forward likelihood Predictive) and ML (Maximum Likelihood) estimation for space-time point processes and seismicity descriptions [6]. In the "Forward Likelihood Predictive" approach (FLP), the outcome for a data set is estimated based on the measure of the ability of the observations. It gives information on the next observation [6]. In the "Maximum Likelihood" method (ML), the parameters of the distribution are such that they maximize the log-likelihood function. This maximizes the agreement of the selected model 
with the observed data. Chiodi and Adelfio [6] suggested that the FLP approach is mostly appropriate for the background seismicity while the ML approach targets the triggered seismicity.

Given a seismic catalog, the package etasFLP is to estimate the whole intensity function in a point of coordinates $(\mathrm{x}, \mathrm{y}, \mathrm{t})$, conditionned to the past history $H_{t}$ [6]:

$$
\begin{gathered}
\lambda_{\theta}\left(x, y, t \mid H_{t}\right)=\mu f(x, y)+\sum_{t_{j}<t} g\left(t-t_{j} \mid m_{j}\right) l\left(x-x_{j}, y-y_{j} \mid m_{j}\right) \\
g\left(t-t_{j} \mid m_{j}\right)=\frac{\kappa_{0} e^{(\alpha-\gamma)\left(m_{j}-m_{0}\right)}}{\left(t-t_{j}+c\right)^{p}}, t>t_{j} \\
l\left(x-x_{j}, y-y_{j} \mid m_{j}\right)=\left\{\frac{\left(x-x_{j}\right)^{2}+\left(y-y_{j}\right)^{2}}{e^{\gamma\left(m_{j}-m_{0}\right)}}+d\right\}^{-q}
\end{gathered}
$$

where : $\mu$ is the first parameter of the ETAS model, which corresponds to the background intensity ; $\mathrm{f}()$ is a density function; $\kappa_{0}$ is a constant and measures the aftershocks productivity; $\mathrm{c}$ and $\mathrm{p}$ are the parameters for the modified Omori's law; $p$ is useful in order to characterize the pattern of seismicity of the given region, indicating the decay rate of aftershocks in time; $m_{j}$ is for the mainshock magnitude; $m_{0}$ is the completeness threshold of magnitude, i.e., the lower bound for which earthquakes with higher magnitude are surely recorded in the catalog; $\alpha$ and $\gamma$ measure the influence on the relative weight of each sequence; $d$ and $q$ are related to the spatial influence of mainshocks [6]

The background seismicity is constrained by the choice of the parameter $m u$. Equations (2)and (3) represent the temporal and the spatial distribution of the induced/triggered seismicity respectively. The temporal distribution for the triggered / induced seismicity is constrained by parameters $\alpha, \mathrm{c}$ and $\mathrm{p}$. The spatial distribution is constrained by the parameters $\mathrm{d}$ and $\mathrm{q}$. In this work, we used the function etasclass to assess the nonparametric and the parametric model. We also compared the FLP and ML approaches by testing the two models.

\section{Results}

The modeling is calibrated through the choices and the computations of the ETAS parameters. These define the parametric and non parametric terms of the intensity function. The latest version of the model (version 2.1.0) was released in July 2020 [7]. The $\gamma$ coefficient is fixed to a constant value. Parameters to investigate the effect of external factors on the triggered seismicity are included. The user can freely choose a value for $\mu$. The choices of $\mu$ and $k_{0}$ influence the ratio between the background events and the triggered ones [7].

\subsection{The ETAS parameters}

Here the gamma coefficient is fixed and set equal to zero. The temporal variation of the triggered seismicity then depends on $k_{0}$. The formula (Equation 2) shows that it decreases with time through the coefficient $\mathrm{c}$ and $\mathrm{d}$. The magnitude threshold was set to 2.5. For a number of iterations limited to 7 , we obtained the ETAS parameters listed in Table 1 :

Table 1. etasFLP model parameters for version 1.4.0 and 2.1.0 package

\begin{tabular}{|c|c|}
\hline & Parameters estimated \\
\hline$\mu$ & 0.015318 \\
\hline$k_{0}$ & 0.120321 \\
\hline $\mathrm{c}$ & 0.005725 \\
\hline $\mathrm{p}$ & 0.931321 \\
\hline $\mathrm{a}$ & no value \\
\hline gamma & 0 \\
\hline $\mathrm{d}$ & 63.161711 \\
\hline $\mathrm{a}$ & no value \\
\hline gamma & 0 \\
\hline $\mathrm{q}$ & 1.656305 \\
\hline
\end{tabular}

Tests considering the FLP option and tests without the FLP (ie. ML) show the same results. Here,consequently, only tests with the FLP option are displayed. The background seismicity is controlled through the choice of $\mu$. Version 2.1.0, which is used in this study, permits us to add covariates data and estimations to better assess the triggered/induced seismicity [7]. In this paper, we present the modeling without this option.

Figure 3 below shows the standard differences between observed and theoretical frequencies obtained for the whole model (background and triggered seismicity).

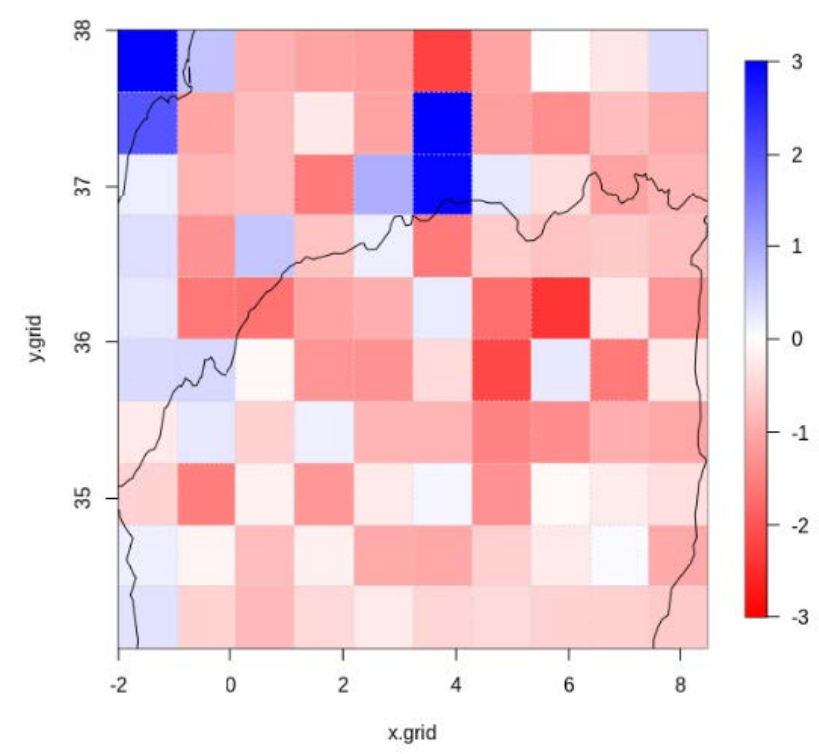

Figure 3. Standard differences between observed and theoretical frequencies for the whole intensity model (Background and triggered seismicity)

On the whole, the computed intensity function reproduces the observed data sets pretty well (see Figure 3). Nevertheless, a high value for the spatial variation of the triggered/induced seismicity illustrated by the coefficients $d$ raises the issue of the convergence of the modeling presented here $(\mathrm{d}=63.15 ; 1.65)$. We also observe discrepancies in Northern Central Algeria (Algiers). These might be due to a lack of data in the region. The resulting ETAS parameters emphasize that the model needs to 
be fitted with more data for the spatial distribution of the triggered events (coefficient d).

\subsection{Background and Triggered Seismicity}

Figures 4 and 5 show the results obtained for the background and the triggered seismicity with the FLP option. The highest intensity is observed for the central part of the country and clusters as well appear in the western and eastern parts of the studied area (Figure 4, Figure 5).

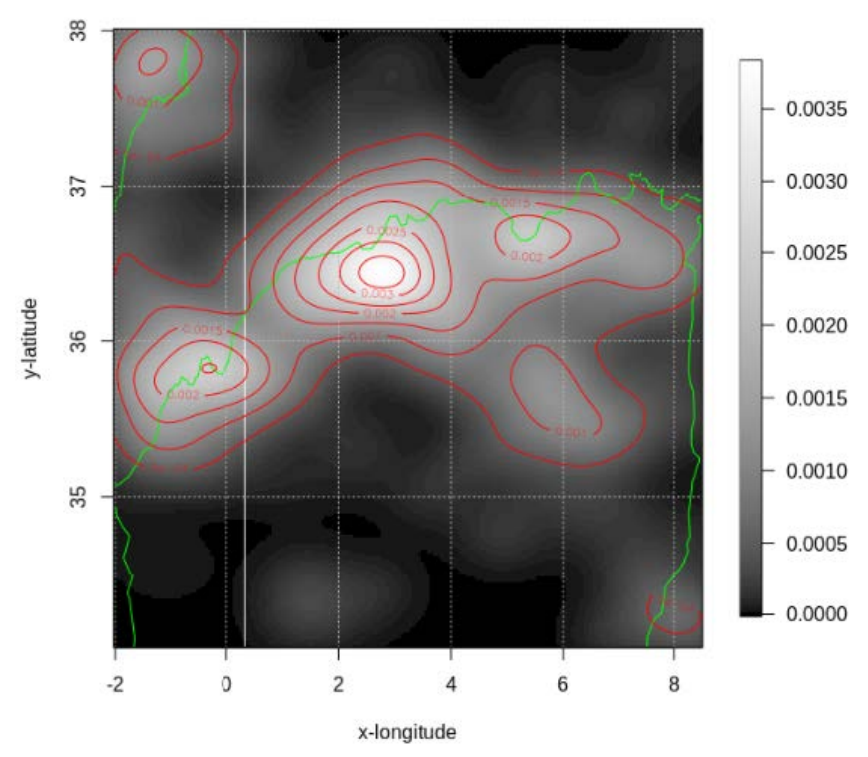

Figure 4. Background Seismicity Model

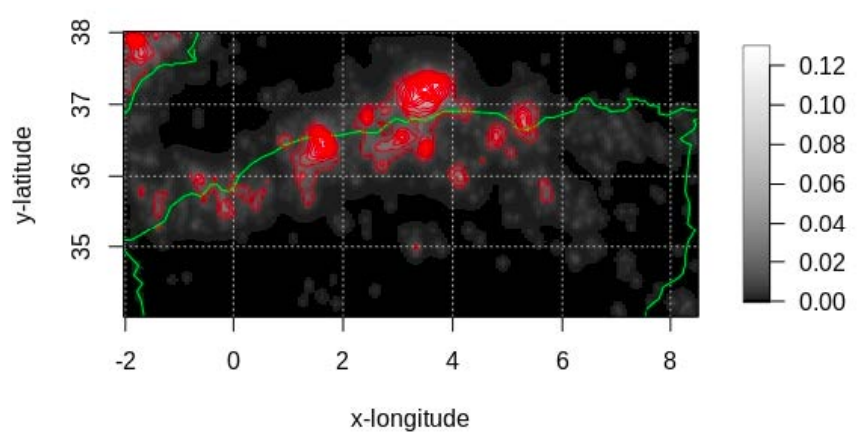

Figure 5. Triggered Seismicity Model

The frequency of the triggered events is less diffuse and looks to be localized in specific regions within the central, western and eastern parts of the country (Figure 5). The highest frequency for the triggered seismicity is located offshore, between $2^{\circ} \mathrm{E}$ and $4^{\circ} \mathrm{E}$. In fact, the modeling reflects more data could help to improve these results.

\section{Discussion}

Earthquake statistical analysis is crucial for suggesting predictive assumptions. Risk mitigation in places prone to seismic hazard relies on probabilistic estimations. Decision-maker and those in charge of urban planning need to know to what extent an area is exposed to a hazard. The development of infrastructures should then consider these studies for the preparedness and protection of those who live in places considered at risk.

The ETAS theory is widely applied to several places for seismic clustering and the estimation of earthquakes' occurrence from a statistical standpoint. Here, the output for the ETAS parameters is in good agreement with other published studies $[6,8]$.The values obtained fall in the same interval and hence represent a comparable distribution between background and triggered seismicity. Nevertheless, the value for the coefficient $d$ indicates more needs to be investigated to improve the spatial distribution of the triggered events.

The physics of earthquakes is complex, and it is a challenging task to estimate and quantify with statistics what is really considered a background tremor and to what extent one event is induced by another.

Firstly, the temporal decay of any aftershock activity is now well represented mathematically in seismology through the theory developed by Omori [9]. Nevertheless, the mix occurrence of a swarm and a main shock-aftershock sequence is a complex process to distinguish for seismic clustering and seismic risk and hazard assessment [10]. Utsu et al [10] discussed on what happen when a large earthquake occur within a swarm. Considering the case of earthquakes swarm due to water pressure and consequently constrained by the temporal behavior of the fluid, they warned that the activity following the earthquake might be regarded as its aftershocks.

On the 30th of November 2007, a seismic swarm was felt and recorded in the Mila region, in northeastern Algeria. From December 2007, Semmane et al. [11] carried out a seismic survey with temporal stations. Hence, thousands of microearthquakes were recorded. Semmane et al. [11] indicated that this unusual seismic crisis was felt by the population of nearby Constantine for a period of about one month and in addition to the shaking, loud-explosion sounding noises preceded the earthquakes. Nearby the epicentral area, the existence of the Oued Athmania reservoir and the pumping activity in the dam that provides water to the population are considered a potential source for the triggering of this seismic swarm. In that context, the construction of a dam with pumping activities near active faults provides explanations for fluids migration within cracks and pore fluid pressure that favors the sliding and the triggered rupture and earthquakes.

Moreover, the ETAS model does not neither include a specific term to represent the contribution of foreshock activity, classically followed by the main shock and then the aftershock series. The largest recorded earthquake that hit the country occurred in El Asnam in October 1980 with a magnitude of 7.3. It is also an earthquake that has been largely and completely recorded from its onset (foreshocks) to the aftershocks that lasted a couple of years later [12].

One year before that earthquake (Ms=7.3, 1980), in November 
1979, Hatzfeld and Ouyed [13] carried out a microearthquake study in the El Asnam area. By that time, one year before the devastating tremor, earthquakes were felt and motivated a survey in the region. The results showed that almost all of the thirteen earthquakes recorded during that experiment were located in the overthrusting block of the El Asnam fault. The thrust mechanism was already shown by these records, with magnitudes that ranged from 0.5 to 1.9 [13]. Later, in the 5 weeks after the main shock, another survey was carried out to record the aftershock activities. Hence, a total of 4517 aftershocks were located [14].

In the present study, data were imported from the ISC website (International Seismological Center). Several events are not recorded in public database, and therefore, lots of tremors are missing. During a swarm, the magnitude can range between 1.3 to higher values. Only a local network can record these shakes. Not having access to these data is one of the main disadvantages of the work here presented. Nevertheless, our paper aims at pointing out the needs to distinct between background and triggered events. Northern Algeria is the location for numerous geothermal and hydrothermal springs and some of them are a natural resource for geo-health and tourism activities. The Central Hauts Plateaux are well-known for their ecosystem related to several wetlands with salted standing lakes. In particular, in the Hodna region, the chott el Hodna is a crucial site to preserve for waterbirds like the Shelduck for example [15]. Man-made activities near active faults may raise an additional environmental risk. Nowadays, protecting ecosystems became one of the main priorities. Contaminated water in places marked by hydrothermal springs should be included as a target and as an essential goal during exploration surveys and man-made activities.

A complete earthquakes database is the key to a successful predictive modeling. Seismic patterns would then be complete and would consequently provide trends for seismic activities in areas defined to be at risk.

\section{Conclusions}

Earthquakes' clustering is an important step that contributes to the understanding of the earthquake nucleation process. Most often, man-made activities are not considered when seismologists process seismic clustering from an earthquake database.

In this paper, stochastic modeling was computed with the etasFLP package from the Comprehensiv R Archive Network depository. Despite the fact that earthquake analysis in Algeria mostly focus on the aftershocks sequence related to a moderate to important tremor, we report here the challenging necessity to include in the cluster analysis more data from the man-made or natural induced shocks related to fault activity and fluid migration. Our modeling was based on a data set available from the ISC network with no more than 2089 events. From the results obtained, these earthquakes do mostly belong to aftershock series. We suggest reconsidering the attempt to reproduce the seismicity pattern of the country by assessing the term related to the covariates in the latest version of the package. To do so, there is a need to create a database with more events, which can reproduce the spatial distribution of the seismicity that was observed and recorded.

\section{Acknowledgements}

We are very grateful to Abdelkader Eddoud from the AUF (University Agency of Francophonia, Campus of Algiers) for all his suggestions and guidance during this work. We also thank the reviewers for their appropriate and constructive suggestions to improve this manuscript.We are grateful to all anonymous who helped to review the manuscript.

\section{REFERENCES}

[1] A. Harbi, S. Maouche, H. Benhallou, "Re-appraisal of seismicity and seismotectonics in the north-eastern Algeria Part II: 20th century seismicity and seismotectonics analysis", Journal of Seismology, Vol. 7 No. 2, pp. 221-234, 2003.

[2] D. Benouar, "Materials for the investigation of the seismicity of Algeria and adjacent regions during the twentieth century", Ann Geofis, Vol. 37, No. 4, pp. 459-860, 1994

[3] I. Abacha, I. Koulakov, F. Semmane, A. Yelles-Chaouche, "Seismic tomography of the area of the 2010 Beni Ilman earthquake sequence, north central Algeria", Journal of the Japan statistical society, Vol. 3, No. 1, pp. 198-207, 2014

[4] Y. Ogata, "Statistical models for earthquake occurrences and residual analysis for point processes", Journal of the American statistical association, Vol. 83, No. 401, pp. 9 - 27, 1988.

[5] Y. Ogata, "Space-time point-processes models for earthquakes occurrences", Annals of the Institute of Statistical Mathematics, Vol. 50, No. 2, 379-402, 1998.

[6] M. Chiodi, G. Adelfio, "Mixed non-parametric and parametric estimation techniques in $r$ package etasflp for earthquakes' description", Journal of statistical software, Vol. 76, No. 3, pp. 1-28, 2017.

[7] G. Adelfio, M. Chiodi, "Including covariates in a spacetime process with application to seismicity, Statistical Methods and Applications",2020, https://doi.org/10.1007/s10260020-00543-5, Springer publications.

[8] T. Kumazawa, Y. Ogata, "Nonstationary ETAS models for nonstandard earthquakes", The Annals of Applied Statistics, Vol. 8, No. 3, pp.1825-1852, 2014.

[9] R. Shcherbakov, D. L. Turcotte, J. B. Rundle, ”A generalized Omori's law for earthquake aftershock decay", Vol. 31, L613, 2004, doi:10.1029/2004GL019808.

[10] T. Utsu, Y. Ogata, and R.S Matsu'ura, "The centery of the omori formula for a decay law of aftershock activity", J. Phys. Earth., Vol. 43, pp. 1-33, 1995 
[11] F. Semmane, I. Abacha, A.K. Yelles-Chaouche, A. Haned, H. Beldjoudi, A. Amrani, "The earthquake swarm of december 2007 in the mila region of northeastern algeria", Nat. Hazards, Vol. 64 No. 4,pp. 1855-1871, 2012.

[12] M. Ouyed, M. Meghraoui, A. Cisternas, J. Frechet, R. Gaulon, H. Philip. "Seismotectonics of the El Asnam Earthquake", Nature, Vol. 292, pp. 26-31, 1981.

[13] D. Hatzfeld, M. Ouyed, "Results of a microearthquake study, one year before the el asnam earth of octobe 10,1980", Tectonophysics, Vol. 89, pp. 33-36, 1982.

[14] G. Yielding, M. Ouyed, G.C.P. King, and D. Hatzfeld, ”Active tectonics of the algerian atlas mountains - evidence from after- shocks of the 1980 el asnam earthquake”, Geophys. J. Int., Vol. 99, pp. 761 - 788, 1989.

[15] C. Bounab, Y. Nouidjem, E. Bensaci, E-Y. Guergueb, A. Chagra, M. Bara, A. Bouzegag, M. Benyahia, M. Houhamdi, "Study of the ruddy shel-duck (tadorna ferruginea) diurnal behavior in chott el-hodna (central hauts plateaux of algeria)", Journal of Entomology and Zoologie Studies, Vol. 5, pp. 1034 1037, 2017. 